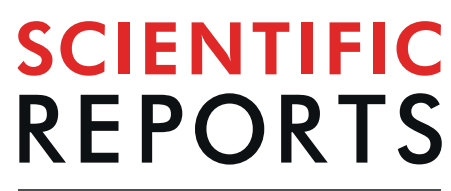

natureresearch

\title{
The ability of damselfish to distinguish between dangerous and harmless sea snakes
}

\begin{abstract}
Claire Goiran $\mathbb{i}^{1}$ \& Richard Shine $\mathbb{i}^{2,3^{*}}$
In defence of their nests or territories, damselfish (Pomacentridae) attack even large and potentially dangerous intruders. The Indo-Pacific region contains many species of sea snakes, some of which eat damselfish whereas others do not. Can the fishes identify which sea snake taxa pose a threat? We recorded responses of damselfishes to natural encounters with five species of snakes in two shallow bays near Noumea, New Caledonia. Attacks by fishes were performed mostly by demersal territorial species of damselfish, and were non-random with respect to the species, size, sex and colouration of the snakes involved. The most common target of attack was Emydocephalus annulatus, a specialist egg-eater that poses no danger to adult fishes. Individuals of a generalist predator (Aipysurus duboisii) that were melanic (and thus resembled $E$. annulatus in colour) attracted more attacks than did paler individuals. Larger faster-swimming snake species (Aipysurus laevis, Laticauda saintgironsi) were watched but not attacked, or were actively avoided (Hydrophis major), even though only one of these species (A. laevis) eats pomacentrids. Attacks were more common towards female snakes rather than males, likely reflecting slower swimming speeds in females. In summary, damselfishes distinguish between sea snake species using cues such as size, colour and behaviour, but the fishes sometimes make mistakes.
\end{abstract}

Individuals of many species are under significant risk of predation and hence, experience intense selection to optimize their responses to potential predators ${ }^{1,2}$. One major challenge is to match the response to the magnitude of threat; for example, the best tactic may be to flee if the predator poses a major risk, but to attack if the predator poses little risk to the individual involved but a substantial risk to its offspring. Multiple types of predators may often be present within the same area, increasing the challenge of correct predator identification ${ }^{4,5}$. Simply treating all potential predators as dangerous is the safest option, but may entail high costs (e.g., of disrupted feeding, interrupted courtship, less effective parental care) from unnecessarily cautious behaviour ${ }^{6,7}$.

In keeping with these ideas, an extensive literature documents sophisticated responses by potential prey to potential predators. For example, the alarm calls of birds can encode information not only about predator species $^{8}$, but also predator behaviour ${ }^{8,9}$ and body size ${ }^{10}$. Likewise, fishes can discriminate between hungry and satiated predators ${ }^{11}$ and salamanders can distinguish the faeces of snakes fed on salamanders versus on alternative prey $^{12,13}$. Lizards can distinguish between high-threat and low-threat predators ${ }^{5,7,14,15}$. Antipredator responses can be innate and/or learned ${ }^{8,16}$ and can change rapidly depending on local conditions ${ }^{17,18}$.

Predation is a major threat to survival for many reef-dwelling fishes ${ }^{19}$, stimulating the widespread evolution of abilities to detect and evade approaching predators ${ }^{20-22}$. In Indo-Pacific coral reef ecosystems, sea snakes from two main lineages (hydrophiine and laticaudine elapids) are abundant and diverse (around 80 species $^{23}$ ) and prey primarily upon fishes ${ }^{24,25}$. Although sea snakes encompass a diversity of body shapes and colours, many taxa are grey to brown with transverse darker bars ${ }^{25,26}$. Perhaps reflecting their recent origin ${ }^{27}$, many "true" (hydrophiine) sea snakes are "notoriously difficult" for most biologists to identify to species ${ }^{28,29}$. Despite those morphological similarities, however, sea snakes exhibit diverse diets. Some taxa feed mostly or entirely on a single type of fish (e.g., Hydrophis stokesii eats only scorpionfish ${ }^{24}$ ) whereas others take a broad range of taxa (e.g., Aipysurus laevis has been reported to consume fish from 12 families ${ }^{24,30}$ ). Often, even closely related (and thus, morphologically similar) species diverge in diets: for example, Aipysurus eydouxii specializes on fish-eggs whereas $A$. duboisii is a generalist predator ${ }^{24}$.

${ }^{1}$ LabEx Corail \& ISEA, Université de la Nouvelle-Calédonie, BP R4, 98851, Nouméa cedex, New Caledonia. ${ }^{2}$ Department of Biological Sciences, Macquarie University, NSW, 2109, Sydney, Australia. ${ }^{3}$ School of Life and Environmental Sciences, University of Sydney, NSW, 2006, Sydney, Australia. *email: rick.shine@mq.edu.au 


\begin{tabular}{|c|c|c|}
\hline Common name & Scientific name & Body length (mm) \\
\hline \multicolumn{3}{|l|}{ Snakes } \\
\hline Reef Shallows Sea Snake & Aipysurus duboisii & $700-800$ \\
\hline Olive Sea Snake & Aipysurus laevis & $1100-1500$ \\
\hline Turtle-Headed Sea Snake & Emydocephalus annulatus & $500-800$ \\
\hline Greater Sea Snake & Hydrophis major & $1100-1500$ \\
\hline Sea Krait & Laticauda saintgironsi & $800-1100$ \\
\hline \multicolumn{3}{|l|}{ Fishes } \\
\hline Scissortail Sergeant & Abudefduf sexfasciatus & 190 \\
\hline Orbicular Damselfish & Amblyglyphidodon orbicularis & 83 \\
\hline Big-lip Damselfish & Cheiloprion labiatus & 60 \\
\hline Twospot Damselfish & Chrysiptera biocellata & 125 \\
\hline Banded Humbug & Dascyllus aruanus & 100 \\
\hline Coral Damselfish & Neopomacentrus nemurus & 80 \\
\hline Obscure Damselfish & Pomacentrus adelus & 85 \\
\hline Ambon Damselfish & Pomacentrus amboinensis & 90 \\
\hline Goldenbrow Damselfish & Pomacentrus aurifrons & 62 \\
\hline Yellowtail Damselfish & Pomacentrus chrysurus & 90 \\
\hline Lemon Damselfish & Pomacentrus moluccensis & 90 \\
\hline Nagasaki Damselfish & Pomacentrus nagasakiensis & 110 \\
\hline Dusky Gregory & Stegastes nigricans & 140 \\
\hline Bluntsnout Gregory & Stegastes punctatus & 130 \\
\hline
\end{tabular}

Table 1. Species of sea snakes and fishes observed in interactions in the Baie des Citrons and Anse Vata, Noumea. Table shows average body lengths of snakes (from Ineich and Laboute 2002), and maximum sizes of fishes (the latter from FishBase. Available at: https://fishbase.org/).

Sea snakes are abundant and speciose in many parts of the Indo-Pacific, with several species often occurring within the same small area ${ }^{25,26}$. Even more abundant and diverse are fishes of the family Pomacentridae (damselfish $)^{31,32}$. In New Caledonian waters, 113 species of Pomacentridae have been recorded ${ }^{33}$. We might expect damselfish to have evolved to recognize which sea snakes are dangerous for themselves or for their clutch and which are not, for the following reasons. First, damselfish lay their eggs on the substrate where they are preyed upon by many other animals, including snakes. Parental defence of the nest is therefore important ${ }^{34}$. Second, damselfish have good visual acuity; they are brightly coloured, and use visual cues to identify fish species when initiating responses to intruders ${ }^{35,36}$. Third, damselfish are capable of learning to discriminate between different types of predators ${ }^{6,36-39}$, even through social cues ${ }^{40,41}$. They can associate different cues ${ }^{42}$, generalize predator recognition to congeneric species ${ }^{39,43}$, and assess predation risk ${ }^{44-48}$. To evaluate the ability of damselfishes to discriminate between sea snakes that consume or do not consume these fish (or their eggs), we gathered standardized data on snake-fish interactions in the course of our fieldwork in two small bays near Noumea, in New Caledonia.

\section{Materials and Methods}

Study site. Baie des Citrons and Anse Vata are small (approx. $1 \mathrm{~km}$ wide) bays beside Noumea, New Caledonia $\left(22^{\circ} 18^{\prime} 10^{\prime \prime} \mathrm{S}, 166^{\circ} 26^{\prime} 08^{\prime \prime} \mathrm{E}\right)$. The substrate is dominated by live coral, coral rubble, and sand ${ }^{49}$. Water depth at high tide in our study site ranges up to $3 \mathrm{~m}$, but extensive areas remain $<1 \mathrm{~m}$ deep even at high tide. Water temperature during the observations averaged $24.04^{\circ} \mathrm{C}\left(\mathrm{SD}=1.78^{\circ} \mathrm{C}\right)$ and water depth averaged $1.80 \mathrm{~m}$ $(\mathrm{SD}=0.71 \mathrm{~m})$. Observations were spread evenly over the tidal cycle (low $35 \%$, medium $25 \%$, high $40 \%$ ).

Study species. We obtained data on 113 natural interactions between fishes and snakes (see Supplementary Materials 1 for video footage of interactions) during fieldwork between February 2012 and September 2016. Most observations were made as a snorkeler swam slowly along behind a moving snake. Observations of snake-fish interactions were made throughout the year (January, $\mathrm{N}=20$ records, February, $\mathrm{N}=21$; March, $\mathrm{N}=15$; April, $\mathrm{N}=3$; June, $\mathrm{N}=2$; August, $\mathrm{N}=19$; September, $\mathrm{N}=12$; October, $\mathrm{N}=7$; November, $\mathrm{N}=1$; December, $\mathrm{N}=13)$. Of the snakes, 30 observations were of the Reef Shallows Sea Snake Aipysurus duboisii, 3 of the Olive Sea Snake A. laevis, 22 of the Turtle-Headed Sea Snake Emydocephalus annulatus, 30 of the Greater Sea Snake Hydrophis major, and 28 of the Yellow-Lipped Sea Krait Laticauda saintgironsi (see Table 1 and Fig. 1 for photographs). The two Aipysurus species are generalist piscivores, and thus pose a potential risk to adult damselfish ${ }^{24}$. The other snake species have specialized diets that do not include adult damselfish: Emydocephalus annulatus eats only the eggs of fishes, Hydrophis major feeds mainly or exclusively on catfish, and Laticauda saintgironsi specializes on eels ${ }^{24,29,34}$.

The fish species involved in interactions with snakes comprised 38 cases with Pomacentrus adelus, 33 with P. moluccensis, 15 with Cheiloprion labiatus, 9 with Stegastes sp., 5 with Amblyglyphidodon orbicularis, 4 with $P$. chrysurus, 2 with P. nagasakiensis, and single cases with Abudefduf sexfasciatus, Chrysiptera biocellata, Dascyllus aruanus, Neopomacentrus nemurus, $P$. amboinensis, and $P$. aurifrons. An additional single case involved either Stegastes nigricans or S. punctatus (the two species are difficult to discriminate when underwater). These fish species span a wide range of sizes, colours and ecologies (Table 1). Some of the interactions doubtless involved the 


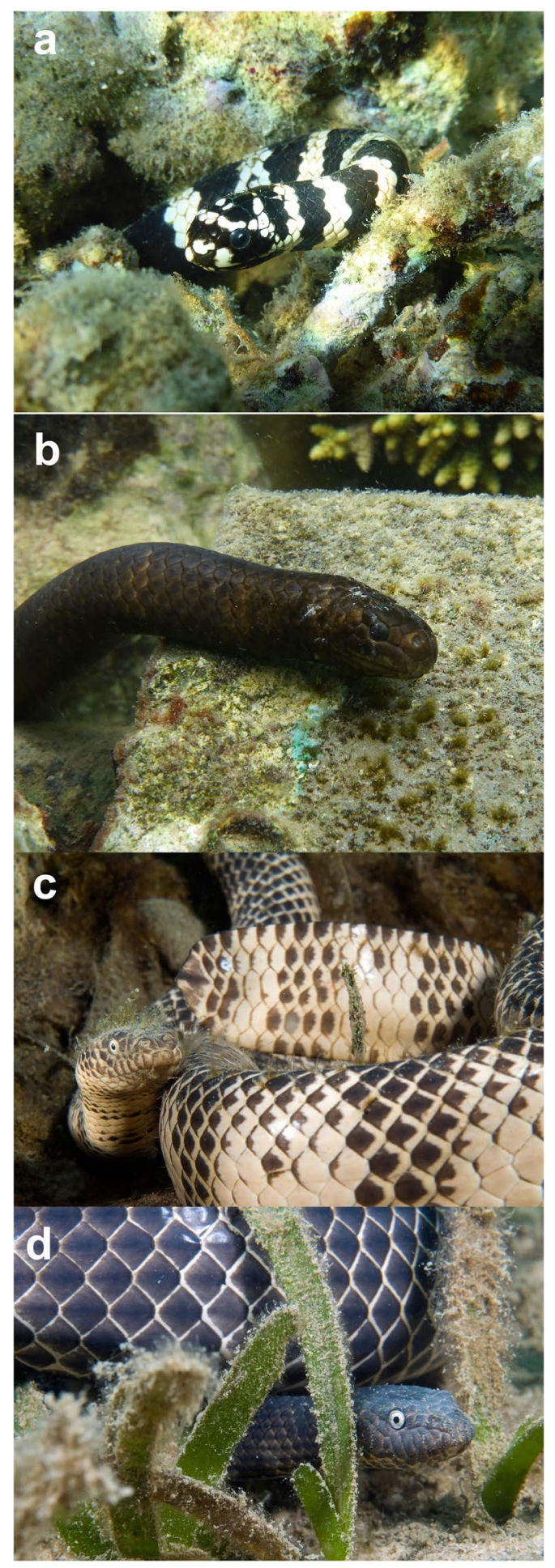

Figure 1. Photographs of colour morphs of two sea snake species found in the study area. Both Emydocephalus annulatus (a,b) and Aipysurus duboisii (c,d) occur in both light and melanic colour phases. Photographs by Claire Goiran $(\mathbf{a}, \mathbf{b})$ and Yves Gillet $(\mathbf{c}, \mathbf{d})$.

same individual snakes and individual fishes but we could not unambiguously identify them and thus, treat each fish-snake encounter as an independent observation.

Data collection methods. In the course of other behavioural-ecology studies ${ }^{34,50,51}$, one of us (CG) snorkelled over fringing reefs, taking notes, photographs and videos documenting the behaviour of sea snakes and fishes. These studies were conducted during daylight hours only ( $0753 \mathrm{~h}$ to $1439 \mathrm{~h}$ ). CG also swam along belt transects in the same area, performing visual fish censuses ( 5 transects $30 \mathrm{~m}$ long and $2 \mathrm{~m}$ wide, between fixed 
points, 3 visual censuses of damselfish, gobies and blennies on each transect per year, in May or June, at high tide, between 0830 and $1030 \mathrm{~h}$ ) over the period May 2012 to May 2018. We used the cumulative number of each fish taxon within the total survey effort as a measure of relative abundance, to compare to the frequencies with which individual fish species were recorded to attack snakes.

We recorded tide (high-low-medium) and water temperature at the beginning of each survey session, and recorded water depth at each observation. Each snake was identified to species and classified into one of three size classes (small, medium, large relative to other members of the same species). We determined sex of adult snakes based on tail shape ${ }^{25,52}$. We also estimated sizes of fishes involved and took notes on aspects such as colour of the snake (for species with different colour morphs).

We defined an interaction between fishes and snakes as any case in which a fish modified its behaviour as a result of the approach of a snake. We classed those behaviours as "flee", "watch" and "attack". We scored an interaction as "attack" if even a single fish out of the group bit or hit the snake. We restricted the current study to pomacentrids because these are abundant at our study site, and they comprised the majority of fishes seen to interact with snakes. In a previous study, we examined nest-defence tactic of gobies and blennies (as well as pomacentrids) towards Turtle-Headed Sea Snakes attempting to consume demersal eggs of those fish species ${ }^{34}$. The present study looks at responses of damselfish to additional snake taxa. We never saw gobies or blennies interacting with any snake species other than E. annulatus.

As well as looking at overall patterns, we examined fish responses to Aipysurus duboisii more closely, because this was the only snake species for which we recorded substantial intraspecific variation in fish responses (i.e., bite vs. not bite the snake). That variation allowed us to investigate factors associated with the responses of fish to snakes.

Statistical analysis. Using JMP Pro 13 (SAS Institute, Cary, NC), we checked normality and variance homogeneity of all continuous variables prior to analysis. We used contingency-table analysis to compare the relative abundances of different genera of fish (based on our overall surveys) with the numbers recorded to attack snakes. We used ANOVA with "species of snake" as the factor to explore variation in the mean sizes and numbers of fishes interacting with different species of snake. To compare conditions where fish attacked versus did not attack, we used that variable as the factor in an ANOVA with either water depth or water temperature as the dependent variable. We used nominal logistic regression to see if the suite of fish genera involved differed among snake species. To evaluate determinants of fish responses, we used nominal logistic regression with whether or not the fish bit the snake as the dependent variable, and snake species and size class (or sex) as the factors. To compare fish responses to tidal phase, we used tide phase (high-low-medium) as the factor, and fish response (attack snake vs. not) as the dependent variable in a nominal logistic regression. We included interaction terms between factors as appropriate, but deleted them if they were non-significant $(p>0.05)$ and recalculated the analyses with main effects only. Where analyses yielded significant results, we used Tukey-Kramer posthoc tests to identify the location of significant differences.

\section{Results}

Species of fishes interacting with snakes. We recorded 7327 fish during our habitat surveys, encompassing nine genera of damselfish (Table 1). The 113 attacks on snakes were primarily by demersal territorial genera (Cheiloprion, Dascyllus, Amblyglyphidodon, Pomacentrus, Stegastes) rather than by mid-water taxa that only exhibit active defence when they are nesting (Abudefduf, Neopomacentrus, Chromis: see Fig. 2). Contingencytable analysis confirmed that the number of attacks relative to fish abundance differed among genera $\left(\chi^{2}=68.08\right.$, $\mathrm{df}=8, p<0.0001)$ and was higher for demersal (territorial) than for midwater (nest-defending) genera $\left(\chi^{2}=30.98, \mathrm{df}=1, p<0.0001\right)$.

Species and numbers of fishes per interaction. The genera of fish recorded to interact with snakes did not differ significantly among the five snake taxa that we studied (nominal logistic $\chi^{2}=26.66, \mathrm{df}=28, p=0.5$ ). However, the mean size of fish interacting with Hydrophis major $(6.33 \mathrm{~cm})$ was greater than that for all other species except Aipysurus laevis (mean $5.00 \mathrm{~cm} ; F_{1,4}=4.12, p<0.004$; posthoc tests show $\mathrm{HM}>\mathrm{LS}=\mathrm{AD}=\mathrm{EA}$; all species means except $\mathrm{HM}$ were 5.0 to $5.4 \mathrm{~cm}$ ). The mean number of fishes involved per interaction also differed among snake species $\left(F_{1,4}=3.44, p<0.015\right)$, ranging from 1.8 for E. annulatus to 21.0 for A. laevis (means from 4.1 to 6.9 in the other three taxa; posthoc tests show $\mathrm{AL}=\mathrm{LS}=\mathrm{AD} ; \mathrm{LS}=\mathrm{AD}=\mathrm{HM}=\mathrm{EA} ; \mathrm{AL}>\mathrm{HM}=\mathrm{EA}$ ).

Effects of snake traits on probability of attack by fishes. Fish were more likely to bite some snake species than others $\left(\chi^{2}=54.63, \mathrm{df}=4, p<0.0001\right)$ and were less likely to bite small snakes than larger ones $\left(\chi^{2}=6.79, \mathrm{df}=2, p<0.035\right.$; interaction term NS so deleted). Inspection of the data show that fish rarely or never bit three species of snakes (A. laevis, H. major, L. saintgironsi), bit A. duboisii in about one-quarter of the encounters, and almost always bit E. annulatus (Fig. 3).

The only species that sometimes attracted bites and sometimes did not (and thus, in which we can further explore determinants of fish attacks) is Aipysurus duboisii. This species shows substantial variation in colouration among individuals within the local population, with melanic individuals resembling melanic E. annulatus ${ }^{53}$ whereas other individuals are pale (see Fig. 1c,d). Logistic regression showed that dark-coloured specimens were more likely to be bitten than were pale-coloured individuals $\left(\chi^{2}=4.68, \mathrm{df}=1, p<0.035\right)$ and that females were more likely to be bitten than males ( 8 of 15 females bitten, vs. 0 of 15 males; $\chi^{2}=9.17, \mathrm{df}=1, p<0.003$; interaction NS so deleted; see Fig. 4). Bites were directed to the head in 22 of 32 cases where we could accurately score bite locations $(69 \%)$, with no significant difference between snake species in this respect $\left(\chi^{2}=1.81, \mathrm{df}=2\right.$, $p=0.41)$. 


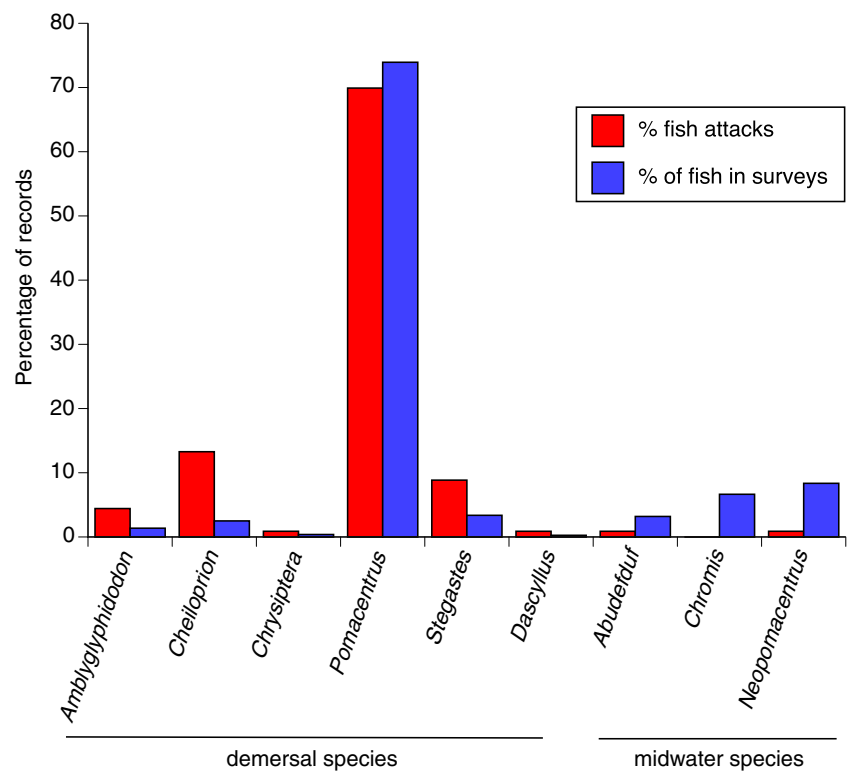

Figure 2. The abundance of damselfish of each genus (based on overall counts during surveys) compared to the number of interactions with snakes recorded for damselfish of each genus. In both cases, numbers are shown as a proportion of total records ( $N=7327$ for surveys, $N=113$ for interactions with snakes). The damselfish genera are divided into those that defend demersal territories, and midwater species that defend against intruders only while they have active nests.

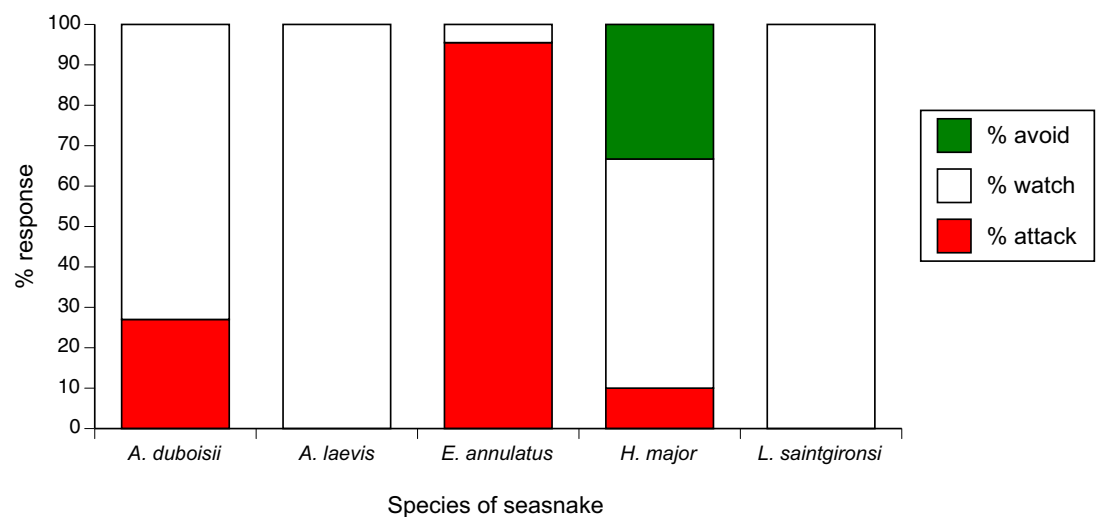

Figure 3. Responses by pomacentrid fishes to encounters with sea snakes of five species (Aipysurus duboisii, Aipysurus laevis, Emydocephalus annulatus, Hydrophis major, Laticauda saintgironsi).

Environmental influences on responses by fishes. Interactions that involved fishes biting snakes occurred in deeper water (mean of $2.13 \mathrm{~m}$ ) than did interactions in which no bites were recorded $(1.68 \mathrm{~m}$; ANOVA, $F_{1,106}=9.97, p<0.003$ ). This effect was not due to different species of snakes being encountered at different depths, because the difference in water depth remained significant after "snake species" was added into the analysis (effect of snake species $F_{4,106}=147.33, p<0.0001$; effect of water depth $F_{1,106}=9.60, p<0.003$; interaction NS so deleted). In the sole species of snake that attracted variable responses (Aipysurus duboisii), the depth effect remains significant $\left(F_{1,28}=18.41, p<0.0002\right.$; mean depth for bites $2.19 \mathrm{~m}$, for no bites $\left.1.32 \mathrm{~m}\right)$.

One potential influence on this water-depth pattern is that snake size may covary with water depth ${ }^{49}$; larger snakes are found in deeper water (in the overall dataset, snake size class vs. water depth: $F_{2,109}=5.37, p<0.006$ ). The same pattern was evident within each of the snake species for which we had data on a range of size classes (Emydocephalus annulatus $F_{2,19}=10.99, p<0.004$; Hydrophis major $F_{2,27}=4.09, p<0.03$; Laticauda saintgironsi $\left.F_{2,25}=29.07, p<0.0001\right)$.

Effects of snake traits on probability of avoidance by fishes. Broadly, the factors that resulted in fishes fleeing from snakes were the opposite of those that stimulated attacks. That is, fishes were less likely to flee if the snake was in deeper water, and if it was a female rather than a male or juvenile. The only species of snake that elicited rapid retreat by fishes was $H$. major, with fish fleeing in 10 of 30 interactions (comparison among species $\chi^{2}=29.39, \mathrm{df}=4, p<0.0001$; see Fig. 3). Within fish that encountered H. major, flight was elicited more often by 
(a) Snake sex/age class

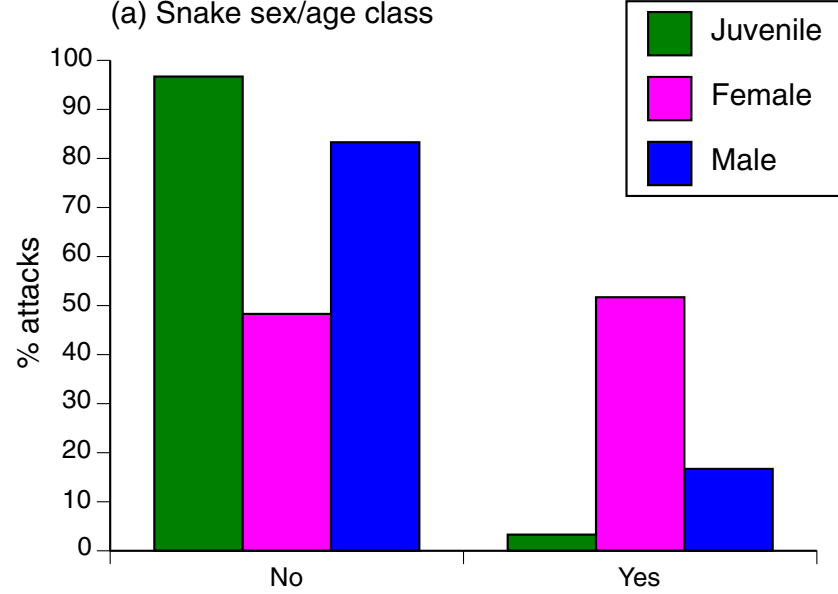

(b) Colour phase of Aipysurus duboisii

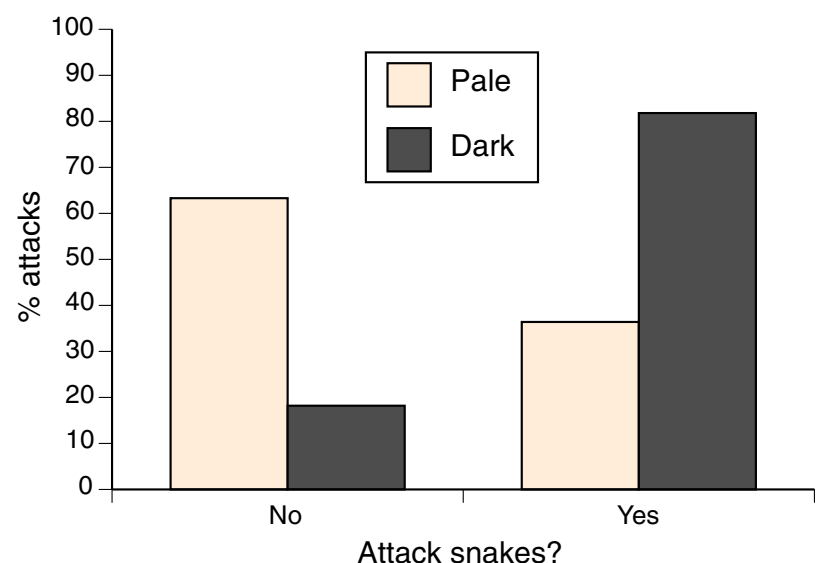

Figure 4. Effects of a snake's sex/age class (upper panel) and colour (lower panel) on the probability that it was attacked by damselfish ("no" = snake was not attacked; "yes" = snake was attacked). The upper panel is based on data from all snake species, whereas the lower panel is based only on data from the colour-polymorphic species Aipysurus duboisii (see Fig. 1 for photographs of those colour phases).

juvenile snakes ( 7 of 11 cases) and males ( 3 of 5 cases) rather than by females ( 0 of 14 cases; effect of sex-age class $\left.\chi^{2}=17.04, \mathrm{df}=2, p<0.0002\right)$.

Determinants of responses by snakes. When bitten by fishes, 8 of 8 A. duboisii fled, as did 18 of 21 E. annulatus. No snakes of other species were bitten, and none fled. Rapid retreat was more likely if the snake was bitten than if it was not bitten (in A. duboisii, $\chi^{2}=24.79, \mathrm{df}=1, p<0.0001$ ). A nominal logistic regression with "snake fled or not" as the dependent variable revealed significant effects of snake species $\left(\chi^{2}=24.80\right.$, $\mathrm{df}=4, p<0.0001$ ), snake size class (larger snakes fled more often; $\chi^{2}=6.05, \mathrm{df}=2, p<0.05$ ), snake sex (females were more likely to flee: $\left.\chi^{2}=10.54, \mathrm{df}=1, p<0.0015\right)$ and whether or not the snake had been bitten by a fish $\left(\chi^{2}=10.72, \mathrm{df}=1, p<0.0015\right)$.

\section{Discussion}

Despite their small body size relative to the snakes that entered their territories (typically, a $60 \mathrm{~mm}$ fish vs. 1 -m-long snake), damselfish are very pugnacious; some species even attack human divers ${ }^{54}$. One of us (CG) was bitten several times by Stegastes sp. while collecting data for this study. Hence, it is not surprising that these small fishes often attacked snakes that entered the fish's territory. The same species of fishes were involved in attacks on all types of snakes. Comparisons with overall abundances (from broad surveys) indicate that the fishes attacking snakes are a non-random subset of the damselfish taxa in the area. Specifically, most attacks on snakes were by damselfish species that defend demersal territories against all comers. Other damselfish taxa, most often seen above the substrate and pugnacious only when defending their nests, accounted for the remaining cases of attacks on snakes.

Anecdotal observations of damselfish biting sea snakes have been recorded by several authors, but always against Emydocephalus ${ }^{26,55,56}$. We recorded attacks against additional species, and these attacks broadly can be divided into two main types of interactions. For one species, the small and slow-moving egg-predator E. annulatus, fish almost invariably attacked the snake and often repulsed it (as described in detail for gobies and blennies as well as damselfish ${ }^{34}$ ). In contrast, fishes almost never attacked three larger, faster-moving species (A. laevis, $H$. 
major, L. saintgironsi). The only exception to this dichotomy was A. duboisii, which is intermediate both in size and in swimming speeds, and was attacked on about $25 \%$ of our observation periods. Intriguingly, this species (a generalist piscivore, and thus a potential danger to adult damselfish) exhibits substantial variation in colouration - and individuals that were dark (and hence, resembled the harmless E. annulatus) were attacked more often than paler individuals (that resembled the larger hydrophiine species).

Interactions between fishes and $E$. annulatus were also distinctive in involving a single fish, whereas most interactions with all of the other snake taxa involved groups of fishes. Numbers may confer safety in this situation, rendering it less likely that an individual fish will be seized by the predator ${ }^{57}$. Broadly, our data on $E$. annulatus support and extend our earlier analysis in the same site, focusing on gobiid and blenniid responses to egg-searching snakes ${ }^{34}$. Our data on responses to the other snake species suggest that these potentially dangerous animals are treated quite differently than is the harmless E. annulatus, albeit with significant attacks to one of those piscivorous taxa (A. duboisii). The concentration of attacks on dark-coloured individuals, and on slow-moving females rather than fast-moving males, suggests that these are cases of mistaken identification by the fishes.

At our study site, some E. annulatus are strongly black-and-white banded rather than melanic ${ }^{53}$. Thus, banded individuals of E. annulatus resemble sea kraits (L. saintgironsi), a species that was never attacked (Fig. 1a and Fig. 3). Why then did fishes direct attacks to banded as well as melanic E. annulatus? If fishes use colour as a criterion for recognizing snake species (as suggested by attacks to melanic A. duboisii), we might have expected them to misidentify banded E. annulatus as another more dangerous species. In practice, however, E. annulatus are also distinctive in their heavyset morphology and very slow movements; and these additional criteria may enable fish to recognize this species regardless of its colour.

In keeping with an influence of non-chromatic cues, the responses by fishes were also affected by snake body size. Juvenile snakes were rarely attacked. One possible reason is that these snakes were too small to pose a threat, because sea snakes are gape-limited predators ${ }^{58}$. However, all of the juvenile snakes that we saw were large enough to swallow most of the fishes that were seen interacting with snakes; and certainly were large enough to swallow eggs of fishes. Thus, we doubt that juvenile snakes were tolerated because they were too small to pose a threat. Instead, the lack of attacks may reflect a tendency for juvenile snakes to be encountered in shallow water, where attacks would be more risky for fishes (because of limited space to evade retaliation by the snake, plus the danger from aerial predators when a fish is focused on the snake). For many other systems, larger predators likely pose more risk and hence attract more intense responses by potential prey (e.g., ground squirrels assessing risk from rattlesnakes ${ }^{59}$ ).

Intriguingly, the probability of attack was also affected by the sex of the snake involved in the encounter. Sexual dimorphism and dichromatism are minor in the snake species involved, suggesting that the differential responses of fishes to male versus female snakes were driven by differences in behaviour rather than morphology. At our study site, most of the female snakes we see are foraging, a behaviour that entails slow movement near the reef structure with frequent tongue-flicking as the snake searches for chemical cues of prey presence. In contrast, males (especially of the four larger species) are more often encountered while they are searching for mates. Of seven males unequivocally scored as "mate-searching" ( $5 \mathrm{~A}$. duboisii, $2 \mathrm{H}$. major), none were attacked by fishes. Mate-searching behaviour involves rapid movement. (e.g., in E. annulatus, swimming speeds of mate-searching males are more than 3 times greater than for foraging snakes ${ }^{60}$ ). In at least one of the species we studied (A. laevis), males are rarely seen in shallow reef sites (such as our study area) except during the mating season ${ }^{6}$. Higher swimming speeds may give the fish less time to react before the snake leaves the fish's territory; and also, may show that the snake is not foraging, and hence is not a direct threat.

In summary, pomacentrid fishes are astute but not infallible at identifying snakes. The response of fishes to snakes may reflect general tactics (reactions to any animal that intrudes into their territory) rather than selection for optimal solutions to the risk posed by snakes. Thus, for example, large animals moving quickly, especially in shallow water, may best be treated as potentially dangerous and hence either watched or avoided. In contrast, a slow-moving snake in deeper water may allow time for fish to assess the degree of threat posed by the snake (to the fish as well as to its eggs) and to react accordingly. Although the potential costs of attacking a piscivorous predator are high, the actual risk may be slight because snakes rarely seize prey in open water. Most sea snakes catch their prey inside crevices in the coral or adjacent soft-bottom substrates ${ }^{25,60,62}$, although some species can capture free-swimming fishes (e.g., Hydrophis platura ${ }^{63}$ ). We never saw a snake strike at a fish that was attacking it; instead, the fish were ignored or avoided.

Future research could usefully explore the generality of our results. For example, how are the responses of fishes affected by environmental factors (such as turbidity of the water) and what role (if any) do chemical cues play? Chemical cues may be important in predator-prey interactions in many aquatic habitats ${ }^{64,65}$, but remain poorly understood ${ }^{66}$ and may be affected by anthropogenic disturbance (e.g., ocean acidification ${ }^{67}$ ). The species of snakes and fishes that we studied are widespread, providing an opportunity to repeat our analyses in different sites. Lastly, the rapid development of robotic models should make it possible for investigators to manipulate aspects such as the size, shape, colour and swimming speeds of snake-shaped objects, and quantify fish responses in an experimental framework.

Received: 2 September 2019; Accepted: 13 January 2020;

Published online: 28 January 2020

\section{References}

1. Relyea, R. A. Morphological and behavioral plasticity of larval anurans in response to different predators. Ecology 82, 523-540 (2001).

2. Apfelbach, R., Blanchard, C. D., Blanchard, R. J., Hayes, R. A. \& McGregor, I. S. The effects of predator odors in mammalian prey species: A review of field and laboratory studies. Neurosci. Biobehav. Rev. 29, 1123-1144 (2005). 
3. Andersson, M., Wiklund, C. G. \& Rundgren, H. Parental defence of offspring: A model and an example. Anim. Behav. 28, 536-542 (1980).

4. Relyea, R. A. How prey respond to combined predators: a review and empirical test. Ecology 84, 1827-1839 (2003).

5. Stapley, J. Differential avoidance of snake odours by a lizard: Evidence for prioritized avoidance based on risk. Ethology 109, 785-796 (2003).

6. Coates, D. The discrimination of and reactions towards predatory and non-predatory species of fish by humbug damselfish, Dascyllus aruanus (Pisces, Pomacentridae). Zeitschrift für Tierpsychologie 52, 347-354 (1980).

7. Webb, J. K., Du, W. G., Pike, D. A. \& Shine, R. Chemical cues from both dangerous and non-dangerous snakes elicit antipredator behaviours from a nocturnal lizard. Anim. Behav. 77, 1471-1478 (2009).

8. Edelaar, P. I. M. \& Wright, J. Potential prey make excellent ornithologists: adaptive, flexible responses towards avian predation threat by Arabian Babblers Turdoides squamiceps living at a migratory hotspot. Ibis 148, 664-671 (2006).

9. Griesser, M. Referential calls signal predator behavior in a group-living bird species. Curr. Biol. 18, 69-73 (2008).

10. Templeton, C. N., Greene, E. \& Davis, K. Allometry of alarm calls: black-capped chickadees encode information about predator size. Science 308, 1934-1937 (2005).

11. Licht, T. Discriminating between hungry and satiated predators: the response of guppies (Poecilia reticulata) from high and low predation sites. Ethology 82, 238-243 (1989).

12. Murray, D. L. \& Jenkins, C. L. Perceived predation risk as a function of predator dietary cues in terrestrial salamanders. Anim. Behav. 57, 33-39 (1999).

13. Ferland-Raymond, B. \& Murray, D. L. Predator diet and prey adaptive responses: Can tadpoles distinguish between predators feeding on congeneric vs. conspecific prey? Can. J. Zool. 86, 1329-1336 (2008).

14. Stuart-Fox, D., Whiting, M. J. \& Moussalli, A. Camouflage and colour change: Antipredator responses to bird and snake predators across multiple populations in a dwarf chameleon. Biol. J. Linn. Soc. 88, 437-446 (2006).

15. Lloyd, R., Alford, R. A. \& Schwarzkopf, L. Chemical discrimination among predators by lizards: Responses of three skink species to the odours of high- and low-threat varanid predators. Austral Ecol. 34, 50-54 (2009).

16. Griffin, A. S. Social learning about predators: a review and prospectus. Anim. Learning Behav. 32, 131-140 (2004).

17. Dickman, C. R. Predation and habitat shift in the House Mouse, Mus domesticus. Ecology 73, 313-322 (1992).

18. Kovacs, E. K., Crowther, M. S., Webb, J. K. \& Dickman, C. R. Population and behavioural responses of native prey to alien predation. Oecologia 168, 947-957 (2012).

19. Hixon, M. A. \& Beets, J. P. Predation, prey refuges, and the structure of coral-reef fish assemblages. Ecol. Monographs 63, 77-101 (1993).

20. Doherty, P. J. \& Sale, P. F. Predation on juvenile coral reef fishes: An exclusion experiment. Coral Reefs 4, 225-234 (1986).

21. Caley, M. J. Predation, recruitment and the dynamics of communities of coral-reef fishes. Mar. Biol. 117, 33-43 (1993).

22. Sale, P. F. The ecology of fishes on coral reefs. (Elsevier, 2013).

23. Rasmussen, A. R., Murphy, J. C., Ompi, M., Gibbons, J. W. \& Uetz, P. Marine Reptiles. PLoS One 6(11), e27373 (2011)

24. Voris, H. K. \& Voris, H. H. Feeding strategies in marine snakes: An analysis of evolutionary, morphological, behavioral and ecological relationships. Am. Zool. 23, 411-425 (1983).

25. Heatwole, H. Sea Snakes, 2nd ed. (University of New South Wales Press Ltd \& Krieger Publishing Company, Malabar, Florida, 1999).

26. Ineich, I. \& Laboute, P. Les serpents marins de Nouvelle-Calédonie. (Institut de Recherche pour le Développement, Paris, 2002).

27. Sanders, K. L. et al. Recent rapid speciation and ecomorph divergence in Indo-Australian sea snakes. Mol. Ecol. 22, 2742-2759 (2013).

28. McDowell, S. B. The genera of sea-snakes of the Hydrophis group (Serpentes: Elapidae). Trans. Zool. Soc. London 32, 189-247 (1972). 29. Greer, A. E. The biology and evolution of Australian snakes. (Surrey Beatty and Sons, Chipping Norton, 1997).

30. Fry, G. C., Milton, D. A. \& Wassenberg, T. J. The reproductive biology and diet of sea snake bycatch of prawn trawling in northern Australia: Characteristics important for assessing the impacts on populations. Pac. Cons. Biol. 7, 55-73 (2001).

31. Quenouille, B., Bermingham, E. \& Planes, S. Molecular systematics of the damselfishes (Teleostei: Pomacentridae): Bayesian phylogenetic analyses of mitochondrial and nuclear DNA sequences. Mol. Phylogenet. Evol. 31, 66-88 (2004).

32. Cooper, W. J., Smith, L. L. \& Westneat, M. W. Exploring the radiation of a diverse reef fish family: Phylogenetics of the damselfishes (Pomacentridae), with new classifications based on molecular analyses of all genera. Mol. Phylogenet. Evol. 52, 1-16 (2009).

33. Fricke, R., Kulbicki, M. \& Wantiez, L. Checklist of the fishes of New Caledonia, and their distribution in the Southwest Pacific Ocean (Pisces). Stuttgarter Beiträge zur Naturkunde A, Neue Serie 4, 341-463 (2011).

34. Goiran, C. \& Shine, R. Parental defence on the reef: Antipredator tactics of coral-reef fishes against egg-eating seasnakes. Biol. J. Linn. Soc. 114, 415-425 (2015).

35. Harrington, M. E. \& Losey, G. S. The importance of species identification and location on interspecific territorial defense by the damselfish, Stegastes fasciolatus. Environ. Biol. Fishes 27, 139-145 (1990).

36. Karplus, I., Katzenstein, R. \& Goren, M. Predator recognition and social facilitation of predator avoidance in coral reef fish Dascyllus marginatus juveniles. Mar. Ecol. Progr. Ser. 319, 215-223 (2006).

37. Kelley, J. L. \& Magurran, A. E. Learned predator recognition and antipredator responses in fishes. Fish Fisheries 4, 216-226 (2003).

38. Mitchell, M. D., McCormick, M. I., Chivers, D. P. \& Ferrari, M. C. O. Generalization of learned predator recognition in coral reef ecosystems: how cautious are damselfish? Funct. Ecol. 27, 299-304 (2013).

39. Mitchell, M. D., McCormick, M. I., Ferrari, M. C. O. \& Chivers, D. P. Coral reef fish rapidly learn to identify multiple unknown predators upon recruitment to the reef. PLoS One 6, el5764 (2010).

40. Manassa, R. P., McCormick, M. I. \& Chivers, D. P. Socially acquired predator recognition in complex ecosystems. Behav. Ecol. Sociobiol. 67, 1033-1040 (2013).

41. Manassa, R. P., McCormick, M. I., Dixson, D. L., Ferrari, M. C. O. \& Chivers, D. P. Social learning of predators by coral reef fish: Does observer number influence acquisition of information? Behav. Ecol. Sociobiol. 68, 1237-1244 (2014).

42. Silveira, M. M., Oliveira, J. J. \& Luchiari, A. C. Dusky damselfish Stegastes fuscus relational learning: evidences from associative and spatial tasks. J. Fish Biol. 86, 1109-1120 (2015).

43. Mitchell, M. D., Chivers, D. P., McCormick, M. I. \& Ferrari, M. C. O. Learning to distinguish between predators and non-predators: understanding the critical role of diet cues and predator odours in generalisation. Sci. Rep. 5, 13918 (2015).

44. Helfman, G. S. Threat-sensitive predator avoidance in damselfish-trumpetfish interactions. Behav. Ecol. Sociobiol. 24, 47-58 (1989).

45. Helfman, G. S. \& Winkelman, D. L. Threat sensitivity in bicolor damselfish: Effects of sociality and body size. Ethology 103, 369-383 (1997).

46. Lönnstedt, O. M. \& McCormick, M. I. Growth history and intrinsic factors influence risk assessment at a critical life transition for a fish. Coral Reefs 30, 805-812 (2011).

47. Bosiger, Y. J., Lonnstedt, O. M., McCormick, M. I. \& Ferrari, M. C. O. Learning temporal patterns of risk in a predator-diverse environment. PLoS One 7, e34535 (2012).

48. Gauff, R. P. M. et al. Influence of predation risk on the sheltering behaviour of the coral-dwelling damselfish, Pomacentrus moluccensis. Environ. Biol. Fishes 101, 639-651 (2018).

49. Shine, R., Shine, T. \& Shine, B. Intraspecific habitat partitioning by the sea snake Emydocephalus annulatus (Serpentes, Hydrophiidae): The effects of sex, body size, and colour pattern. Biol. J. Linn. Soc. 80, 1-10 (2003). 
50. Goiran, C., Dubey, S. \& Shine, R. Effects of season, sex and body size on the feeding ecology of turtle-headed sea snakes (Emydocephalus annulatus) on IndoPacific inshore coral reefs. Coral Reefs 32, 527-538 (2013).

51. Goiran, C. \& Shine, R. Reaction of a sea snake (Hydrophis major) to contact with a sea anemone. Coral Reefs 33, 793 (2014).

52. Shine, R. \& Shetty, S. The influence of natural selection and sexual selection on the tails of sea-snakes (Laticauda colubrina). Biol. J. Linn. Soc 74, 121-129 (2001).

53. Goiran, C., Bustamante, P. \& Shine, R. Industrial melanism in the seasnake Emydocephalus annulatus. Curr. Biol. 27(16), $2510-2513$. e2 (2017).

54. Randall, J. E. Reef and shore fishes of the South Pacific: New Caledonia to Tahiti and the Pitcairn Islands. (University of Hawaii Press, Honolulu, 2005).

55. Minton, S. A. \& Dunson, W. W. Sea snakes collected at Chesterfield Reefs, Coral Sea. Atoll Res. Bull. 292, 101-108 (1985).

56. Guinea, M. L. Functions of the cephalic scales of the sea snake Emydocephalus annulatus. J. Herpetol. 30, 126-128 (1996).

57. Lehtonen, J. \& Jaatinen, K. Safety in numbers: The dilution effect and other drivers of group life in the face of danger. Behav. Ecol. Sociobiol. 70, 449-458 (2016).

58. Voris, H. K. \& Moffett, M. W. Size and proportion relationship between the beaked sea snake and its prey. Biotropica 13, 15-19 (1981).

59. Swaisgood, R. R., Owings, D. H. \& Rowe, M. P. Conflict and assessment in a predator-prey system: Ground squirrels versus rattlesnakes. Anim. Behav. 57, 1033-1044 (1999).

60. Shine, R., Bonnet, X., Elphick, M. J. \& Barrot, E. G. A novel foraging mode in snakes: Browsing by the sea snake Emydocephalus annulatus (Serpentes, Hydrophiidae). Funct. Ecol. 18, 16-24 (2004).

61. Lynch, T. P. The behavioural ecology of the olive sea snake, Aipysurus laevis. Doctoral dissertation, James Cook University of North Queensland (1999).

62. Voris, H. K., Voris, H. H. \& Liât, L. B. The food and feeding behavior of a marine snake, Enhydrina schistosa (Hydrophiidae). Copeia 1978, 134-146 (1978)

63. Kropach, C. The yellow-bellied sea snake in the eastern Pacific. In: The biology of sea snakes, (ed. Dunson, W.) 185-213 (University Park Press, Baltimore, 1975).

64. Kats, L. B. \& Dill, L. M. The scent of death: Chemosensory assessment of predation risk by prey animals. Ecoscience 5, 361-394 (1998).

65. Schoeppner, N. M. \& Relyea, R. A. Interpreting the smells of predation: How alarm cues and kairomones induce different prey defences. Funct. Ecol. 23, 1114-1121 (2009).

66. Ferrari, M. C. O., Wisenden, B. D. \& Chivers, D. P. Chemical ecology of predator-prey interactions in aquatic ecosystems: A review and prospectus. Can. J. Zool. 88, 698-724 (2010).

67. Dixson, D., Munday, P. L. \& Jones, G. P. Ocean acidification disrupts the innate ability of fish to detect predator olfactory cues. Ecol. Let. 13, 68-75 (2010).

\section{Acknowledgements}

Approvals to conduct the research were provided by the Province Sud, New Caledonia (permit 3252-17/ARR/

DENV). The work was supported by the Australian Research Council (grant FL120100074).

\section{Author contributions}

C.G. initiated the study and gathered the data; R.S. conducted statistical analyses; C.G. and R.S. jointly interpreted the data and wrote the manuscript.

\section{Competing interests}

The authors declare no competing interests.

\section{Additional information}

Supplementary information is available for this paper at https://doi.org/10.1038/s41598-020-58258-2.

Correspondence and requests for materials should be addressed to R.S.

Reprints and permissions information is available at www.nature.com/reprints.

Publisher's note Springer Nature remains neutral with regard to jurisdictional claims in published maps and institutional affiliations.

(c) (i) Open Access This article is licensed under a Creative Commons Attribution 4.0 International

License, which permits use, sharing, adaptation, distribution and reproduction in any medium or format, as long as you give appropriate credit to the original author(s) and the source, provide a link to the Creative Commons license, and indicate if changes were made. The images or other third party material in this article are included in the article's Creative Commons license, unless indicated otherwise in a credit line to the material. If material is not included in the article's Creative Commons license and your intended use is not permitted by statutory regulation or exceeds the permitted use, you will need to obtain permission directly from the copyright holder. To view a copy of this license, visit http://creativecommons.org/licenses/by/4.0/.

(C) The Author(s) 2020 